\title{
Interconnecting Governments, Businesses and Citizens - A Comparison of Two Digital Infrastructures
}

\author{
Bram Klievink, Anneke Zuiderwijk, Marijn Janssen \\ Delft University of Technology, Delft, The Netherlands \\ \{A.J.Klievink; A.M.G.Zuiderwijk- \\ vanEijk;M.F.W.H.A.Janssen $\}$ @tudelft.nl
}

\begin{abstract}
Public and private organizations in various areas are setting up digital Information Infrastructures (IIs) for interconnecting government, businesses and citizens. IIs can create value by sharing and integrating data of multiple actors. This can be the basis for value added services and especially collaborations of public and private partners can make IIs thrive. Easier access to integrated services and products (jointly) offered by government and businesses may stimulate transparency and innovations. IIs are under development in many domains, including for open data and international trade. However, there are notable differences in the design, characteristics and implementation of the IIs. The objective of this paper is to compare two diverse IIs in order to obtain a better understanding of common and differing elements in the IIs and their impact. Among the differences are the roles of government, businesses and users, in driving, developing and exploitation of the IIs.
\end{abstract}

Keywords. public-private networks $\cdot$ digital infrastructure $\cdot$ information infrastructure $\cdot$ platforms $\cdot$ information exchange $\cdot$ broker $\cdot$ e-government

\section{Introduction}

Governments around the world are in the stage of setting-up digital information infrastructures (IIs) to enhance the fulfillment of their public tasks and enhance collaboration with businesses and citizens. Actors have a diverse set of associated components or services and IIs interconnect them and support connecting a variety of users and providers to each other. These digital IIs may interconnect governments with businesses and citizens to support collaboration between them.

Collaborating in digital infrastructures alters the relationship between government, businesses and the public. For government this is a recent phenomenon added to traditional information sharing approaches. Budget cuts, increased interdependence among a multitude of actors in networks and with blurring boundaries between governments, businesses and the public have led scholars to emphasize that governments need to collaborate with the private sector and other actors to organize public action [1-6]. This has resulted in a plea for governments to change the way they collaborate. The

This is the author's version of this paper. The final publication is published in volume 8653 of the series Lecture Notes in Computer Science (pp. 84-95) and is available at Springer via http://dx.doi.org/10.1007/978-3-662-44426-9_7 
solution here is concerted action by a variety of actors by leveraging existing ICTs and re-use of the original information that already exists somewhere. This goes beyond just connecting the IT and information systems of actors to each other and includes socio as well as technical aspects of great heterogeneity [7, 8].

Digital information infrastructures are interconnected system collectives [9], through which information existing within organizations can be used and shared, also across organizational boundaries $[8,10]$. Although these infrastructures often have (in some form) already been available for decades, this often concerns 'closed' systems that are used by a limited number of users and governed by a single actor. Inspired by web-based social media and business platforms, recently the focus is on opening up systems and seeking value in using them for connecting organizations and people.

Information infrastructures are used to describe shared, heterogeneous systems that are continuously evolving as actors generate new functionalities based on the information infrastructures, which are in turn also shared [8]. Information infrastructures can be used by a wide variety of actors, with both usages, roles and types of actors evolving over time [11]. Consequently, there is not a single owner or controller of digital IIs and they should be flexible enough to include new services and functionality to adapt to the changing customer needs.

Since recently, digital IIs are also being developed for their potential to support the re-use of data and functionality of private sector infrastructures by government and for sharing and integrating data of the actors involved in the II $[12,13]$. This could result in easier access to integrated public and private services and products for citizens and increased transparency and innovations in both the public and private sector.

Various types of IIs can be identified, including open data IIs and IIs for logistics and trade. In these types, the type of actors that play a role, the functionalities and the institutional and technical designs all vary. This raises the question in which respect they are different and if and how they can learn from each other.

These differences may indicate that these digital IIs can be used for public action in different ways, and this could provide opportunities for learning from each other. Comparing digital IIs on various aspects is useful in order to obtain a better understanding of the common and differing elements in the IIs and to identify the factors that affect the variation in IIs and which factors influence their impact. This understanding could contribute to the development of new IIs and the improvement of existing IIs. The objective of this paper is to develop a framework for comparing IIs and to use the framework for comparing two digital information infrastructures.

This paper is organized as follows. In the following section we describe our approach. Subsequently, we assess relevant literature as a first step for developing a framework. We then compare two digital information infrastructures and in the process provide further detailing of the framework. One II concerns a business infrastructure also supporting government tasks, the other is a government infrastructure focused on the general public. We end with conclusions and a future research agenda. 


\section{Research Approach}

This research contributes to the existing literature and digital government practice offering first steps towards developing a framework for comparing IIs, based on literature a comparison of two digital information infrastructures. In this section we describe the research approach for attaining this objective. The main components of our approach are:

1. A literature review for identifying II characteristics. There we describe various articles to identify aspects that play a role in government use of digital information infrastructures. We describe literature related to infrastructures, information infrastructures, digital infrastructures, boundaries between the public and the private sector, and network effects.

2. A case comparison. As the objective is enhancing our understanding of digital information infrastructures in the context of interconnecting government, businesses and citizens, a qualitative, case study-based approach was used [14]. A qualitative approach was employed to get an in-depth understanding of the cases. Theoretical sampling was used to select the cases, which is appropriate since we aim to explore a relatively new field and stimulate the extension of emergent theory and provide examples [15]. To sample the cases, a list of criteria for case characteristics was developed:

- The cases employ established digital information infrastructures;

- The cases represent various levels of openness and maturity;

- The cases represent digital IIs on various geographical levels;

- Case study information should be available and accessible.

We opted for comparing platforms with varying degrees of openness, maturity and geographical coverage, as much can be learned from a comparison of these contexts. A multiple-case design is used, since this is preferred over single-case designs, as multiple cases provide more compelling evidence [16]. Furthermore, the use of multiple cases from different contexts could expand the external generalizability of the research findings compared to a single case study. Based on the criteria, the following two cases were selected:

- European open government data II; focussed on connecting and engaging data publishers (governments) and users of open data (businesses and citizens). The infrastructure is open for both providers and users. It connects to services and functionalities provided by others and enables new actors to connect to it. The development started in 2011, and the first phase is currently being finalized. The geographical coverage is worldwide and is currently available in nine languages (including English, Chinese, German, French and Bahasa Indonesia).

- Global trade data II; focuses on exchanging trade data amongst business actors. The infrastructure can be used to gather data for government (needed for performing key government functions), but government cannot provide the infrastructure functionality directly. This is a business II, in which the degree of openness depends on the role of each actor. The development also started in 2011, and the II is continuously being refined and expanded. It has global coverage. 
By exploring different types of cases, we were able to compare them and identify common and different aspects. The two cases were investigated by using a variety of research methods, including interviews, user group discussions, observations in project meetings, reading reports and investigating publicly available documents and websites. A data collection protocol covered the purpose, the multi-sided user base, the functionality and services, decision-making, and the role of government. Table 1 displays the sources of data for the two cases.

Table 1. Overview of the information sources that were used in the case studies in this research

\begin{tabular}{l|ll}
\hline Methods used & Case 1: Open data II & Case 2: Logistics data II \\
\hline One-to-one interviews & 1 & 11 \\
User group discussions & 5 & 9 \\
Project meetings & 7 & 15 \\
Reports and documents & 19 & 35 \\
Websites & 2 & 2 \\
\hline
\end{tabular}

\section{Towards a Framework for Comparing Digital Information Infrastructures}

This section provides background information derived from investigating the literature. There is not much literature in which digital IIs are related to their roles in the interconnections between government, citizens and businesses. We therefore identify characteristics of IIs that are core to the concept and relevant to this domain. A key characteristic of infrastructures is that "they are used by many different users, with the usage evolving over time, as may the type of users" [11]. Digital infrastructures can be viewed as socio-technological systems that emerge and evolve through the interplay of technology, users, providers, and policy-makers [11]. In the context of this research, digital infrastructures can also be viewed as (part of) IIs. From a broad perspective an II includes technological and human components, networks, systems and processes that contribute to the functioning of a specific information system [17]. Hanseth and Lyytinen [7] define an II as "a shared, open (and unbounded), heterogeneous and evolving socio-technical system (which we call installed base) consisting of a set of IT capabilities and their user, operations and design communities" (p. 4). Following this definition, IIs comprise both the IT and (inter-)organizational structures (e.g. networks). Furthermore, IIs typically also comprise the users of the infrastructure, network operators, and other actors and components. These technological and social structures are the basis for facilities and services, which in turn can be used by actors, society and economies for key functions [8]. IIs offer a potential for transformation of the way actors interact and organize (economic) activity. Although often used to describe the evolving nature of technology from a business or common perspective, IIs also impact and even reshape the organizations and their services in the public sector [11]. Especially the large amounts of data that are accessible through them offer tremendous potential for innovation in the public and private sector. Ex- 
amples of IIs are the internet and wireless service infrastructures, which have shown considerable benefits for individuals, businesses and society [7].

With regard to the interconnection and networks of governments, businesses and citizens, the literature shows that many operations of government transcend the boundaries between the public and the private sector [e.g. 18]. As governments cannot themselves realize all public action, they will have to organize public action instead. The main challenge for this is that the private sector business models should be aligned with the action and values that have to be created by government organizations [19]. As value is not created by a single actor in the network but by coordinating the organisations in the public-private network, public value creation is not exclusively the domain of the government [20]. Since business focus on making money and profitability is essential for their long-term survival, public values like equal access might clash with private sector values like competition and efficiency [21]. Only at relatively high costs access can be given to all, which reduces the profitability. Private sector actors might therefore not be interested in providing equal access to all service consumers. In connecting to other parties in platforms, a balance should be struck between enabling businesses to find a business model, and government's values.

Therefore, responsibilities for the development, operations and maintenance of the II should be defined carefully. Development of infrastructures and governance are intertwined. Managing the interdependencies between parts of the infrastructure is crucial for ensuring stable operations. Furthermore, since various actors are involved in the development, maintenance and governance of digital IIs, network effects are crucial to make an infrastructure work. Network effects or network externalities refer to the dependence of the value of a good or service on the number of other people who use it [22]. Key in IIs is that they are shared; various actors can extend the infrastructure and integrate it with their own operations and thereby facilitate II emergence [13]. Through the II, actors can connect to systems of other actors in the network, and these systems become part of the infrastructure as well. As this happens over multiple tiers, this adds to the complexity. An important characteristic of IIs is the installed base; this is both an additional factor complicating the development of IIs (as the installed base includes a variety of (legacy) systems), and is necessary for the II to add value, as the benefit of connecting to an II becomes bigger the larger the installed base is. This concerns users, developers, and providers of data and services. The characteristics following from the foregoing are summarized in Table 2.

Table 2. Elements for a framework for the comparison of digital information infrastructures.

\begin{tabular}{l|l}
\hline Characteristic of (digital) (information) infrastructures & Source \\
\hline $\begin{array}{l}\text { Emerge and evolve through the interplay of technology, users, } \\
\text { providers, and policy-makers }\end{array}$ & {$[11,13]$} \\
$\begin{array}{l}\text { Used by many different users } \\
\text { Usage evolving over time }\end{array}$ & {$[8,11]$} \\
$\begin{array}{l}\text { Type of users evolving over time } \\
\text { Socio-technological systems }\end{array}$ & {$[8,11]$} \\
$\begin{array}{l}\text { Networks, systems and processes that contribute to the functioning } \\
\text { of a specific information system }\end{array}$ & {$[1,11]$} \\
\hline
\end{tabular}




\begin{tabular}{l|l}
\hline Installed base and critical mass, including (strategies) for expan- & {$[7,23,24]$} \\
sion and cultivation & \\
Facilities and services based on II, that actors use to function & {$[8,13]$} \\
Interactions between public and private sector & {$[25]$} \\
Decision and governance structures & {$[23,25]$} \\
\hline
\end{tabular}

\section{Framework and Findings from the Case Study Comparison}

The II in the first case has been developed approximately two years ago and is focused on connecting and engaging data publishers and users of open government data. The II is used to make government data mainly from the social sciences and humanities domain available to citizens, businesses and other stakeholders in Europe to contribute to the realisation of open data advantages, such as increased transparency [26, 27], strengthened citizen engagement [28] and improved policy and decision making $[26,27]$. The II interconnects governments, businesses and citizens by integrating data derived from many European open government data portals with services and functionalities developed by businesses to analyse, curate and visualise these data and the use of these data and services by citizens. The II is open in the sense that any organization, business or person can use the II and contribute to it by adding datasets and applications that are not available in the II yet or by connecting extended (e.g. cleansed) datasets and the results of data use to the original dataset. It is available worldwide, and is localized in (currently) nine languages, including many of the world's biggest languages. This greatly enhances the usability for citizens all over the world. The open data II can be found via http://www.engagedata.eu/. More information about the project in which this II was created is available at http://www.engage-project.eu/.

The second case concerns a private information infrastructure for exchanging global trade and logistics data amongst business actors for government supervision and control purposes. In the domain of global supply chains, innovations are currently undertaken to enhance data sharing and the timely availability of accurate data in global trade networks. This concerns business information infrastructures, but given the strong role of regulation and compliance (e.g. tax, security) this also requires intensive information exchange with, among others, customs authorities. The infrastructure is designed for enhancing information sharing between business actors involved in global trade, but can also be used to combine data for government purposes and thereby support compliance. This is a business platform, in which the degree of openness depends on the role of each actor. The government is one of the stakeholders, but cannot steer or provide the II nor its functionality directly. This II is not directly publicly accessible. More information about the project in which this II was created is available at http://www.cassandra-project.eu/.

Table 3 provides an overview of the main results, in the form of an application of the characteristics mentioned in Table 2. Table 3 includes the theoretical characteristics of the framework in direct application to the cases, and is the basis for comparison. Some characteristics also follow from the cases and the comparison, thereby 
further developing the comparison framework. Given the nature of IIs as a sociotechnical concept, both technical and non-technical elements are part of the comparison. The table provides background to the qualitative comparison of the two information infrastructures, which follows after the table.

Table 3. Comparing the two cases of digital information infrastructures.

\begin{tabular}{|c|c|c|c|}
\hline & II characteristics & Case 1: Open data II & Case 2: Logistics data II \\
\hline \multirow{7}{*}{ 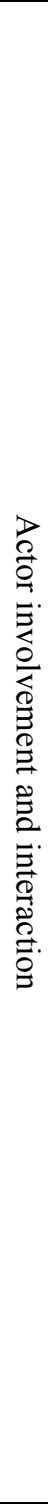 } & $\begin{array}{l}\text { Actors involved in } \\
\text { the design }\end{array}$ & $\begin{array}{l}9 \text { initiating project } \\
\text { partners (university and } \\
\text { research, and business- } \\
\text { es) from various Euro- } \\
\text { pean countries }\end{array}$ & $\begin{array}{l}\text { Consortium of } 26 \text { partners } \\
\text { (government, universities, } \\
\text { IT providers and logistics } \\
\text { providers, from various } \\
\text { European countries }\end{array}$ \\
\hline & $\begin{array}{l}\text { Actors involved in } \\
\text { the use }\end{array}$ & $\begin{array}{l}\text { Open government data } \\
\text { suppliers and users }\end{array}$ & $\begin{array}{l}\text { Business involved in trade } \\
\text { or logistics, IT solution } \\
\text { providers, government } \\
\text { inspection agencies }\end{array}$ \\
\hline & $\begin{array}{l}\text { Number of actors } \\
\text { involved in the use }\end{array}$ & $1000+$ & $\begin{array}{l}\text { Actors from seven global } \\
\text { trade flows (each spanning } \\
\text { two continents) involved }\end{array}$ \\
\hline & $\begin{array}{l}\text { Type of users and } \\
\text { usage evolving } \\
\text { over time }\end{array}$ & $\begin{array}{l}\text { Yes, as the II and its } \\
\text { services change, the } \\
\text { type of users and usage } \\
\text { also changes }\end{array}$ & $\begin{array}{l}\text { Yes, starts with including } \\
\text { data sources, systems and } \\
\text { functionality of core group } \\
\text { of users (traders and cus- } \\
\text { toms), expanding over } \\
\text { time (other businesses and } \\
\text { government agencies) }\end{array}$ \\
\hline & $\begin{array}{l}\text { Interactions be- } \\
\text { tween public and } \\
\text { private sector }\end{array}$ & $\begin{array}{l}\text { Yes, the II provides } \\
\text { tools for the private } \\
\text { and public sector to } \\
\text { interact (e.g. requests } \\
\text { for data provision; } \\
\text { discussing about what } \\
\text { can be learned from } \\
\text { data use) }\end{array}$ & $\begin{array}{l}\text { Yes, government agencies } \\
\text { re-use business data from } \\
\text { the II for assessments of } \\
\text { trade lanes. Businesses use } \\
\text { added value functionality } \\
\text { for compliance purposes }\end{array}$ \\
\hline & $\begin{array}{l}\text { Openness and } \\
\text { costs }\end{array}$ & $\begin{array}{l}\text { Free to use. Open for } \\
\text { anyone to publish and } \\
\text { use raw or processed } \\
\text { open government data }\end{array}$ & $\begin{array}{l}\text { Distributed architecture } \\
\text { with interface based on } \\
\text { global open standard; can } \\
\text { be implemented directly or } \\
\text { via IT solution with added } \\
\text { services }\end{array}$ \\
\hline & $\begin{array}{l}\text { Strategies for cre- } \\
\text { ating critical mass } \\
\text { and for attracting }\end{array}$ & $\begin{array}{l}\text { Social media (Twitter, } \\
\text { LinkedIn, Facebook), } \\
\text { workshops, websites, }\end{array}$ & $\begin{array}{l}\text { Individual exploitation } \\
\text { plans for all partners, in- } \\
\text { cluding value propositions }\end{array}$ \\
\hline
\end{tabular}




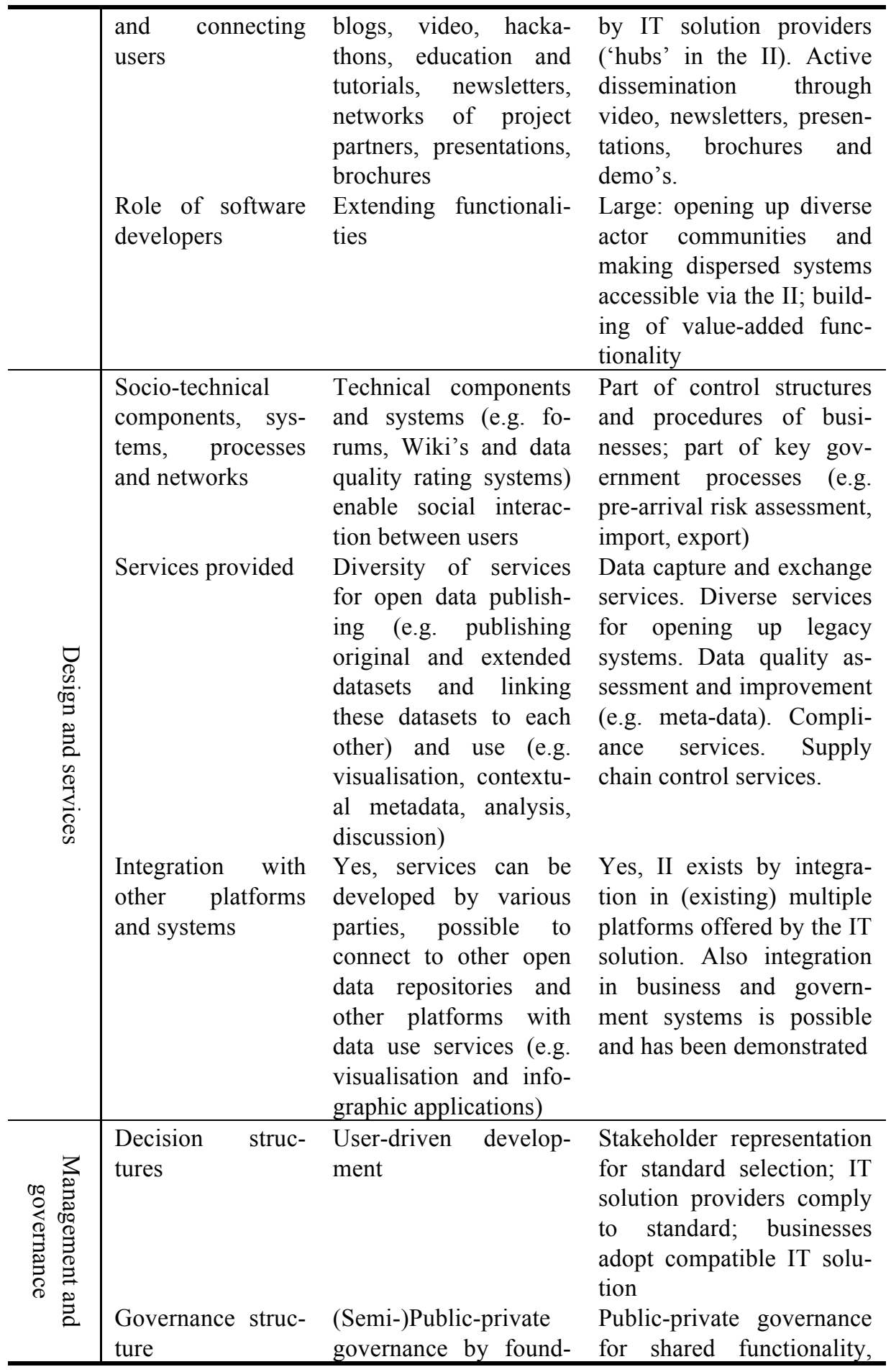




\begin{tabular}{l|l}
\hline & ing organizations and data requirements and \\
& governance by users of exchange. \\
& the II, both aiming at \\
& shared functionality, \\
& data requirements and \\
data and service ex- \\
change.
\end{tabular}

In the first case, the II is operated by a semi-public organization, while in the second case the II is operated by a variety of business actors, each controlling a part of the II, joined-up by using open standard based interfaces. In both cases, the information infrastructure is designed in collaboration with various other (semi-) public and private organizations. Both digital infrastructures make use of data and information provided by government agencies. Moreover, in both cases governments do not only provide data and information, but they can also be users of the digital information infrastructure. Yet, they are not involved in its development. The functionalities provided by the infrastructure are not key government functions and this enables innovative use of public data, without governments having to do it themselves. The government, however, has an interest to steer the business development in a way that leads to a solution that is also able to serve the public function (invisible hand).

Not only government agencies can use the IIs. Both IIs have functionalities that are shared between and can be used by both (semi-) public and private parties. In the first case these functionalities can also be used by citizens. For instance, there are functionalities to discuss what can be learned from the use of open government data. Governments, private organizations and citizens can all use this one functionality in different ways. Governments can use it to adapt their data publishing strategies and policies, while companies can use it to find out how one can innovate with these open data, and citizens can use it to make more informed decisions in everyday life. The second case also has functionalities that can be used by both public and private parties, but citizens cannot directly use the functionalities of this II.

Salient differences are also attributed to the governance. A significant difference between the two cases is that the digital II in the first case is user-centric, whereas the second case is driven by IT solution providers and logistics service providers. Those parties need to make value propositions to other parties involved in global trade (buyers, sellers, inspection agencies) to have them join as well, which is vital as they are important providers of data and users of services. This is necessary to ensure a critical mass and make it interesting for government agencies to gather information from the II. In turn, the fact that governments can also use it, is relevant for businesses in their decision to adopt it, as this opportunity supports compliance and is capable of reducing the administrative burden for the business community. The II in the first case cannot function without contributions of its users, since its value depends on social interaction between and collaboration of users. For example, if users would not share data, services and what can be learned from these with each other, the II becomes less valuable to other users. For this infrastructure it is very important to create strategies for obtaining a critical mass and for attracting and connecting users. While the European Commission currently funds the infrastructure, finding a self- 
sustainable model for the infrastructure is challenging, since it is not desirable to sell open government data. One of the core principles of open government data is that they should be available for free [e.g., 29, 30, 31]. A potential solution for this could offer business models in which users do not pay for the data, but for the use of data services, such as data curation and analysis.

Finally, a key difference can be found in the actors involved in the design of the infrastructure. The first case involved nine project partners who designed the II based on requirements that were identified in the literature, interviews a survey and workshops. Three private organizations were involved, but the design of the II was not based on the way that they already used open data in practice or on the way that they wanted to use open data in the future. The private organizations were mainly involved in the II design to explore the open data field rather than to deliver an II that they aimed to use themselves. In contrast, the second case of 26 partners employed a 'Living Lab' methodology in which existing trade lanes of the project partners were used to implement, test and refine the development of the infrastructure [32]. In this way, for each trade lane, a host of business partners got involved that were not part of the project consortium, but play a key role in providing the data required, and in using the functionality based on it. In this case, the involved private organizations were also interested in the use of the II themselves.

\section{Conclusions and Discussion}

In this explorative study, we have compared various characteristics of IIs that are used to interconnect government organizations, businesses and citizens. As a next step in our research we will compare more IIs, selected based on varying characteristics on the key dimensions we identified in this study (both the theoretical characteristics and those found in the case comparison). In future research, we will further refine the key characteristics of digital infrastructures we found in this study to come to a definitive framework and testable propositions, which we will use in a comparison of more IIs.

Among the key characteristics we found in this study are that governments can 'connect' to these infrastructures and steer those parts that need to be steered (e.g. with incentives or via regulations) to ensure that effective public action is realized and that public values are respected or created. Also, it is important to acknowledge that IIs consist of emerging parts. This makes it impossible to fully predict and design the direction of the development in advance. The type of uses that are enabled by the II, as well as the types of actors that are involved, can evolve in unforeseen ways. Actors will attempt to steer it in a direction that suits them, but have limited means for doing so. Therefore, a key challenge for IIs is establishing in what form quality and development directions will be determined and governed, whilst catering for the requirement that IIs need to be flexible to adapt to events that shape their evolution. Still, as actors change their ways of working based on the II, robustness and stability are required, which means that these have to be accommodated by the technological design (e.g. via open standards) and the organizational design (clear responsibility and gov- 
ernance structures), especially related to accountability in case of errors. Some of these characteristics are similar to those playing a role in open source software [33].

There are various notable differences in the design, characteristics and implementation of digital IIs that interconnect government, businesses and citizens. For instance, some IIs are user driven, while others use more formal consultations for their design, and the type of data and services involved may vary. If digital infrastructures do not arise bottom-up (e.g. from a community of businesses or others), governments may have to create or facilitate an environment in which businesses take up the functionality, for example by providing key information that can form the basis of the infrastructure. This requires businesses to have some kind of revenue model or other incentives. Depending on the functionality, governments need to warrant that certain (public) values are met. The policy implications of this should be amongst the key topics for further research.

Finally, governments may operate some components of the information infrastructure itself. This can for example happen with components of the vital infrastructures of society, including digital and information infrastructures. This can help ensuring critical mass. However, to meet the efficiency and effectiveness requirements of government, businesses need to operate most of it.

Acknowledgements. This paper results from the CASSANDRA project (FP7; SEC2010.3.2-1, grant agreement no. 261795) and the ENGAGE project (FP7; INFRA2011-1.2.2, grant agreement no: 283700), which are supported by funding from the 7th Framework Programme of the European Commission. Ideas and opinions expressed by the authors do not necessarily represent those of all project partners.

\section{References}

1. Dunleavy, P., Margetts, H., Bastow, S., Tinkler, J.: New Public Management Is Dead-Long Live Digital-Era Governance. Journal of Public Administration Research and Theory 16, 467-494 (2006)

2. Fountain, J.E.: Paradoxes of Public Sector Customer Service. Governance 14, 55-73 (2001)

3. Milward, H.B., Provan, K.G., Fish, A., Isett, K.R., Huang, K.: Governance and Collaboration: An Evolutionary Study of Two Mental Health Networks. Journal of Public Administration Research and Theory 20, i125-i141 (2010)

4. Pollitt, C., Bouckaert, G.: Public Management Reform: a Comparative Analysis. Oxford University Press, Oxford (2004)

5. Salamon, L.M. (ed.): The Tools of Government: A Guide to the New Governance. Oxford University Press, Oxford (2002)

6. Stoker, G.: Public Value Management: A New Narrative for Networked Governance? The American Review of Public Administration 36, 41-57 (2006)

7. Hanseth, O., Lyytinen, K.: Design theory for dynamic complexity in information infrastructures: the case of building internet. Journal of Information Technology 25, 1-19 (2010)

8. Tilson, D., Lyytinen, K., Sørensen, C.: Digital Infrastructures: The Missing IS Research Agenda. Information Systems Research 21, 748-759 (2010) 
9. Henfridsson, O., Bygstad, B.: The Generative Mechanisms of Digital Infrastructure Evolution. Mis Quarterly 37, (2013)

10. Gal, U.: Boundary Matters: The Dynamics of Boundary Objects, Information Infrastructures, And Organisational Identities. vol. PhD. Cape Western Reserve University (2008)

11. Janssen, M., Chun, S.-A., Gil-Garcia, J.R.: Building the next generation of digital government infrastructures. Government Information Quarterly 26, 233-237 (2009)

12. Tan, Y.-H., Bjørn-Andersen, N., Klein, S., Rukanova, B. (eds.): Accelerating Global Supply Chains with IT-Innovation. ITAIDE Tools and Methods. Springer, Berlin (2011)

13. Klievink, B., Van Stijn, E., Hesketh, D., Aldewereld, H., Overbeek, S., Heijmann, F., Tan, Y.-H.: Enhancing Visibility in International Supply Chains: The Data Pipeline Concept. International Journal of Electronic Government Research 8, (2012)

14. Benbasat, I., Goldstein, D.K., Mead, M.: The Case Research Strategy in Studies of Information Systems. MIS Quarterly 11, 369-386 (1987)

15. Eisenhardt, K.M.: Building Theories from Case Study Research. Academy of Management Review 14, 532-550 (1989)

16. Yin, R.K.: Case study research. Design and Methods. SAGE publications, Thoasand Oaks (2003)

17. Braa, J., Hanseth, O., Heywood, A., Mohammed, W., Shaw, V.: Developing health information systems in developing countries: The flexible standards strategy. MIS Quarterly 31, 381-204 (2007)

18. Milward, H.B., Provan, K.G.: Managing the Hollow State: Collaboration and Contracting. Public Management Review 5, 1-18 (2003)

19. Janssen, M., Kuk, G., Wagenaar, R.W.: A Survey of Web-based Business Models for eGovernment in the Netherlands. Government Information Quarterly 25, 202-220 (2008)

20. Jørgensen, T.B., Bozeman, B.: Public values an inventory. Administration \& Society 39, 354-381 (2007)

21. Rosenau, P.V.: Introduction. The Strengths and Weaknesses of Public-Private Policy Partnerships. American Behavioral Scientist 43, 10-34 (1999)

22. Katz, M., Shapiro, C.: Network Externalities, Competition and Compatibility. American Economic Review 75, 424-440 (1985)

23. Constantinides, P.: Perspectives and implications for the development of information infrastructures. Information Science Reference (2012)

24. Hanseth, O., Monteiro, E., Hatling, M.: Developing information infrastructure: The tension between standardization and flexibility. Science, Technology \& Human Values 21, 407426 (1996)

25. Klievink, B., Janssen, M., Tan, Y.-H.: A Stakeholder Analysis of Business-to-Government Information Sharing: the Governance of a Public-Private Platform. International Journal of Electronic Government Research 8, (2012)

26. Bertot, J.C., Jaeger, P.T., Grimes, J.M.: Using ICTs to Create a Culture of Transparency: E-government and Social Media as Openness and Anti-Corruption Tools for Societies. Government Information Quarterly 27, 264-271 (2010)

27. Janssen, K.: The Influence of the PSI Directive on Open Government Data: An Overview of Recent Developments. Government Information Quarterly 28, 446-456 (2011)

28. Huijboom, N., Broek, T.v.d.: Open Data: an International Comparison of Strategies. European Journal of ePractice 4-16 (2011)

29. http://assets.sunlightfoundation.com/policy/Open

Data

Policy Guidelines/OpenDataPolicyGuidelines_V2.pdf (accessed April 8, 2014)

30. http://opengovdata.io/ (accessed April 8, 2014) 
31. http://opendefinition.org/ (accessed April 8, 2014)

32. Klievink, B., Lucassen, I.: Facilitating adoption of international information infrastructures: a Living Labs approach. Lecture Notes in Computer Science Proceedings of IFIP EGOV 2013, Koblenz, Germany, (2013)

33. Gallivan, M.J.: Striking a balance between trust and control in a virtual organization: a content analysis of open source software case studies. Information Systems Journal 11, 277-304 (2001) 